\title{
Editorial
}

\section{Difficult questions in music education}

In the last editorial of the British Journal of Music Education (Fautley \& Murphy, 2015) we gave some thought to the various ways in which music education manifests itself in teaching and learning situations in a variety of contexts. One of the many roles that the $B J M E$ fulfils is to document the changing nature of music education, as represented in the articles which are submitted to it, and subsequently published. But this does not mean that we should not also be asking difficult questions as to what the purposes of music education are, or might be. This is particularly the case when we consider the international nature of the readership of the BJME. What counts as music education in one national context may be very different from that which is practised elsewhere.

Let us take the case of generalist classroom music education. This needs defining, as for some contexts it does not exist. Generalist classroom music takes place in schools, from the very youngest children, through to secondary education and beyond. It does not necessarily involve specific tuition on a single instrument (although it might), but takes as its aim a broad approach to understanding music, often across a range of styles and genres. Then let us contrast this with individuated music education which is formal, takes place in a studio or specific learning room, and takes as its aim the notion of developing specific instrumental or vocal skills and technique. Are these at different ends of a music education continuum? Or do they represent different bright points within a constellation of music education? These are important questions, as the whole nature of what is meant by 'music education' might hinge on an understanding of one of these. This is not an idle debate, but one that comes to the fore in times of recession, and a global tightening of financial belts. All too often behind both of these approaches is an accountant with a set of spreadsheets. The question can all too quickly become not 'Which sorts of music education would we like?' But instead 'Which sorts of music can we afford?' Or 'Which sorts of music education do we want to pay for centrally, and which sorts do we want to transfer financial responsibility for onto parents and carers to pay?' And these questions matter - who pays for music education? Who should pay? Who benefits?

There are some jurisdictions where generalist classroom music is downplayed, and group ensemble work takes up the majority of teaching and learning curriculum time. In some cases such ensembles are the entirety of music education. They are often elective, and focused principally upon a performing modality. Proponents of this sort of music education often decry generalist forms as they do not see the latter producing instrumentalists of a high calibre. On the other hand, in places where generalist music is the norm, teachers argue they are able to develop creativity and composing skills which a close performance focus may struggle to accommodate. Again, this is not to say that either of these are wrong per se, but that there are different foci in each. Questions for the performing centred modality might involve how to foster and develop creativity and composing, and for the generalist how to enable sufficient instrumental skill-sets so that creative ideas can be realised by the children and young people involved. 
What is difficult to determine is which form is better, or even why we might worry about which form is better - after all, what is 'better'? There are historical and cultural mores at stake here, and some jurisdictions may be reluctant to move from long-established delivery patterns. Alongside the global austerity enforced belt-tightening which is taking place throughout the developed world at the moment, we in music education are often finding that we are having to argue our cause and 'fight our corner' with increasing frequency. Advocacy can take up a lot of time and energy. But this takes us to the crux of the matter, and invokes the important question 'What are the purposes of music education?'. Doubtless, there are many well-meaning responses to this which discuss the transferability of learning music, such as 'music makes you better at mathematics', 'music makes you better at literacy', 'music makes you better at social skills', and so on. The danger with this focus is that if music is only there to make you better at something else, why not just do the something else instead? After all, coarse and fly fishing with rod-and-line is supposed to increase patience and self-awareness, yet we do not hear of many schools where it is on the curriculum! In a similar vein any purported intrinsic benefits of music learning can mean very little to those who hold the purse strings when it comes to deciding where what little money there is should be spent. Advocacy for music education is all well and good, but with multiple simultaneous competing advocates for a whole range of subject and domain areas, all the noise may not help those whose job it is to prioritise. Indeed, as Wayne Bowman observes:

Debates over the relative merits of music's intrinsic and extrinsic values have a remarkably long history in music education. For the most part, however, these debates have generated more heat than light. Zealous advocacy movements have recently breathed new life into tired old debates about the relative merits of music's 'inherent' and 'instrumental' benefits, most often without questioning the legitimacy of their segregation into mutually exclusive (intrinsic/extrinsic) value domains. (Bowman, 2013, p. 3)

Which means that what we might wish to do instead of asking 'Why teach music?' is to ask ourselves 'Why am I teaching music?', and this question cannot and should not be asked without the linked question 'What do my learners learn that is meaningful to them from my teaching?'. After all, we may be teaching simply to put food on our tables. Does it matter what we teach? Does it matter how we teach it? Does it matter why we teach? These are actually very difficult questions to answer properly. Sometimes it is all too easy to get caught up in the undoubted busy-ness of quotidian existence to worry about these. But worry we should. Here is Wayne Bowman again:

In short, 'music' names a tremendously diverse and powerful set of human practices that may serve ends both desirable and undesirable, both beneficial and detrimental. Whether the value of a given musical or instructional practice is good or bad depends on whether, how, and the extent to which it enables its practitioners or beneficiaries to thrive. (Bowman, 2013, p. 4)

Simply saying that music is intrinsically good simply will not 'not cut the mustard', as the old British saying goes. Statements such as these have little value philosophically, 
ethically, or politically. But we keep hearing them! We do need to keep a close eye on ourselves in music education. For example, we often hear that some forms of music education are preparing children and young pupils for an outmoded model of society and music-making which no longer exists. Is this true? Are there systems predicated on preparing children and young people to work in what Lydia Goehr (1992) referred to as 'the imaginary museum of musical works'? Are we wanting a sort of living-history re-enactment? In which case what does 'authenticity' mean? Or, to take an argument which appears to be at the opposite end of the spectrum, should we be preparing children and young people for 21 st century skills, and jobs which may not exist yet? In which case we must ask what this actually means in terms of music education? To do this we need to ask ourselves if 19th and 20th century European systems of music education travel well in place and time, and what a 21 st century system actually means in practice.

So, what we have to decide from all of this is what are our personal values in music education, how they mesh (or not) with the important features, foci, mores and hegemony of contemporary society, and what are the potential impacts on our learners. And those discussions are very likely to be played out in the pages of the British Journal of Music Education, which means that we can interrogate them from our own perspectives.

And so to the current issue where we open with Jennie Henley's research on using Cultural Historical Activity Theory (CHAT) to analyse the relationship between developing identity, developing musicianship and transformative processes. Henley systematically provides a comprehensive critique of the two-dimensional model of CHAT and then shows how her more elaborate, three-dimensional model can provide deeper insights on how experiences in music education can be considered. The exemplification of theory through relevant music education projects provides rich material for future research and the evolution of the model.

Addressing the perennial question of confidence amongst primary generalist teachcers, Michele Biasutti, Sarah Hennessy and Ellen de Vugt-Jansena describe how an intensive programme for primary teachers from Austria, Italy, the Netherlands and Slovenia had both an immediate and longer-term impact on teacher confidence and creative approaches to teaching. This intervention illustrates how intensive and timely professional development opportunities can make a positive contribution to teacher confidence and efficacy in music education.

Anna Ehrlin draws attention to music in preschool in a Swedish context. Although music education may be designed to serve different functions within a learning institution such as a preschool, as Ehrlin observes, the leadership of the institution is crucial to the enactment of the music education goals in practice.

The complexity of the working lives of musicians is illustrated through rich data by Adele Teague and Gareth Dylan Smith. As the authors report, music graduates begin their working lives with a range of ambitions that are realised to a greater or lesser extent depending on various performance, teaching and other work opportunities. Inherent in the resulting portfolio careers are varying levels of job satisfaction, work-life balance issues and identities as musicians. The complexities of these experiences merit ongoing research to ensure that higher education institutions are attuned to the future lives of students.

In looking at what classical musicians can learn from working with actors, Ken Rea reports on a two-year study that involved musicians working alongside actors on two 
devised performance projects. The power of a creative intervention is again illustrated here where the projects demonstrate that, even a year later, some of the musicians manifested noticeable benefits in their mainstream playing, including greater levels of confidence, creativity and presence.

Finally, Anne-Marie L. Czajkowski and Alinka E. Greasley report the development and implementation of a unique Mindfulness for Singers (MfS) course designed to improve singers' vocal technique. In an evaluation of the course, the results showed benefits of daily mindfulness exercises on breathing, micro-muscular awareness, vocal tone, text communication and problem solving. Moreover, a blind controlled study indicated that the participating vocal students could be distinguished from their peers as a result of the course. The study draws attention to a growing body of research in the field of mindfulness where the possibility of its application in music education contexts raises further, tantalising research questions.

MARTIN FAUTLEY and REGINA MURPHY

BJME Co-editors

\section{References}

Bowman, W. (2013) The ethical significance of music-making. Music Mark Magazine, 3, Winter 2013/14. London: Music Mark.

Fautley, M. \& Murphy, R. (2015) Editorial. What is music education? British Journal of Music Education, 32, $1,1-4$.

Goehr, L. (1992) The Imaginary Museum of Musical Works. Oxford: Clarendon Press. 